Jussi Heinonen MD, Markku Salmenperä MD, Martti Suomivuori MD

\title{
Contribution of muscle relaxant to the haemodynamic course of high-dose fentanyl anaesthesia: a comparison of pan- curonium, vecuro- nium and atracurium
}

To define the role of muscle relaxants in haemodynamic responses to high-dose $\left(75 \mu \mathrm{g}^{-\mathrm{kg}^{-1}}\right)$ fentanyl anaesthesia and to noxius stimuli associated with intubation and sternal spread during coronary artery bypass surgery, we compared haemodynamics between three groups of pa-

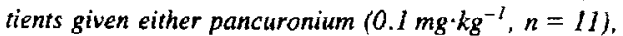
vecuronium $\left(0.086 \mathrm{mg}^{\circ} \mathrm{kg}^{-1}, n=\right.$ II) ar atracurium $(0.43$ $m g \cdot \mathrm{kg}^{-1}, n=12$ ). Additional doses of the relaxants were given to maintain a 90 per cent neuromuscular block. $\mathrm{Pa}$ tients given pancuronium showed no increases in mean values of heart rate, arterial pressure or cardiac output during the induction of anaesthesia or after intubation, whereas a decrease in these variables was observed in the vecuronium group. The haemodynamics in the atracurium group were intermediate compared with the other two study groups. In spite of a decrease in coronary perfusion pressure, no patient given vecuronium developed myo-

\section{Key words}

NEUROMUSCULAR RELAXANTS: pancuronium, vecuronium, atracurium; ANAESTHETICS, intravenous: fentanyl; ANAESTHESIA; cardiovascular.

From the Cardiothoracic Anaesthesia Group, Department of Anaesthesia, Helsinki University Central Hospital, Helsinki, Finland.

Address correspondence to: Dr. J. Heinonen, Dept. of Anaesthesia, Helsinki University Central Hospital, Haartmaninkatu 4, SF-00290 Helsinki 29, Finland. cardial ischaemia. An actvantage of vecuronium over pancuronium and atracurium was an attenuation of the blood pressure response to sternotomy. Patients given atracurium had a small increase in pulmonary vascular re. sistance during sternotomy. Our patients continued their beta-adrenergic antagonist medication until the morning of the day of operation and they were pretreated with a small intravenous dose of diazepam $\left(0.1 \mathrm{mg} \cdot \mathrm{kg}^{-1}\right)$ before induction of anaesthesia. These drugs may have prevented the deleterious haemodynamic effects observed by some investigators after the administration of pancuronium during high-dose fentanyl anaesthesia.

Pancuronium has been widely used as a muscle relaxant during high-dose fentanyl anaesthesia for cardiac surgery. The rationale for this practice is that the vagolytic and sympathomimetic effects of pancuronium tend to antagonise the vagally mediated bradycardia resulting from fentanyl administration. ${ }^{1}$ However, in some patients the heart rate accelerating effect of pancuronium may exceed the bradycardic effect of fentanyl. ${ }^{1,2}$ Furthermore, pancuronium may also exaggerate circulatory responses to noxius stimuli. ${ }^{3}$ Since these properties of pancuronium may be harmful in patients with limited coronary vascular reserve, studies have been done to find out whether another neuromuscular blocking drug or drug combination might prove safer for these patients. ${ }^{2,4-6}$

Vecuronium and atracurium are new muscle 
relaxants without vagolytic and sympathomimetic effects (the absence of the latter effect in the case of atracurium is, however, not well documented).$^{7-11}$ Like pancuronium, vecuronium does not release histamine. ${ }^{12}$ Atracurium does cause release of histamine but in amounts less than those produced by metocurine or tubocurarine. ${ }^{13}$ Thus, vecuronium and atracurium should be potentially useful muscle relaxants for cardiac patients.

In our previous study, pancuronium did not accelerate heart rate over the awake control level but only reversed the decrease in heart rate and cardiac output caused by fentanyl, whereas vecuronium further decreased these parameters. ${ }^{6}$ In that study, succinylcholine was administered for intubation, and pancuronium or vecuronium was administered later. It is therefore possible that the haemodynamic effects of pancuronium and vecuronium were modified by the effect of succinylcholine on the autonomic nervous system ${ }^{14}$ or by the delay of the administration of the nondepolarising relaxant. The present study differs from the previous one in that the nondepolarising relaxant was given before intubation and a patient group receiving atracurium was included.

\section{Methods}

\section{Patients}

Thirty-four patients scheduled for elective coronary artery bypass grafting (CABG) were studied. We excluded patients with significant valvular disease, those with critical narrowing of the left main coronary artery, and patients with ejection fraction $<0.40$, as estimated by cineangiocardiography. The patients were randomly allocated to three groups, receiving either pancuronium, vecuronium or atracurium in a blind fashion. Beta-adrenergic blocking drugs and calcium entry blockers were continued up to the morning of the operation day. The patients gave their consent to the study, which had been approved by the Ethical Committee of the institute.

\section{Anaesthesia}

On the evening before operation the patients were given pentobarbitone $100-200 \mathrm{mg}$ and promethazine $25-50 \mathrm{mg}$ orally. As premedication all patients received $0.2 \mathrm{mg} \cdot \mathrm{kg}^{-1}$ morphine and $0.006 \mathrm{mg} \cdot \mathrm{kg}^{-1}$ scopolamine intramuscularly. On arrival in the operating theatre, an intravenous infusion of Ringer's acetate solution was started and $0.1 \mathrm{mg}$. $\mathrm{kg}^{-1}$ of diazepam was given intravenously in divided doses. During preparation of the monitoring, patients received $10 \mathrm{ml} \cdot \mathrm{kg}^{-1}$ of Ringer's acetate and thereafter a constant infusion of $2 \mathrm{ml}$. $\mathrm{kg}^{-1} \cdot \mathrm{h}^{-1}$. Radial arterial and triple-lumen pulmonary arterial catheters were inserted under local anaesthesia (one per cent lidocaine). During the preparation for anaesthesia the patients were given 35 per cent oxygen via a venturi mask.

Anaesthesia was induced with fentanyl at a rate of $7.5 \mu \mathrm{g} \cdot \mathrm{kg}^{-1} \cdot \mathrm{min}^{-1}$ to a total dose of $75 \mu \mathrm{g} \cdot \mathrm{kg}^{-1}$. Three minutes after the start of the fentanyl infusion, a bolus dose of either pancuronium $0.1 \mathrm{mg}$. $\mathrm{kg}^{-1}$. vecuronium $0.086 \mathrm{mg} \cdot \mathrm{kg}^{-1}$ or atracurium $0.43 \mathrm{mg} \cdot \mathrm{kg}^{-1}$ was given intravenously from a blinded syringe. Seven minutes after the administration of the muscle relaxant, the larynx and trachea were sprayed with four per cent lidocaine, $2 \mathrm{ml}$, and the trachea was intubated.

Ventilation was first assisted or controlled manually with 100 per cent oxygen using a nonrebreathing valve and, after intubation, controlled with a mixture of oxygen and air $\left(\mathrm{FIO}_{2} 0.50\right)$ using the nonrebreathing circuit of a Servo $900 \mathrm{~B}$ ventilator. Respiratory rate was 12 breaths $\mathrm{min}^{-1}$ and the tidal volume was adjusted to maintain $\mathrm{PaCO}_{2}$ at a normal level.

The degree of neuromuscular block was estimated using supramaximal ulnar nerve stimulation and quantitation of the evoked electromyographic response (NT-monitor, Organon). A neuromuscular block of at least 90 per cent was maintained by giving one-fifth of the initial dose of the relaxant when needed.

\section{Study design and measurements}

Systemic arterial pressure, pulmonary arterial pressure, central venous pressure and the $V_{5}$ lead of the ECG were recorded throughout the study. More detailed haemodynamic measurements were made at the following times: (1) Five to ten minutes after the insertion of the vascular catheters. (2) Two minutes after the administration of the muscle relaxant. (3) Seven minutes after the administration of the muscle relaxant, immediately before intubation. (4) Immediately after intubation. (5) Before the start of surgery. (6) After sternal spread.

Haemodynamic measurements included heart 
TABLE I Preoperative data

\begin{tabular}{llll}
\hline & Pancuronium & Atracurium & Vecuronium \\
\hline $\mathrm{N}$ (female/malc) & $1 / 10$ & $0 / 12$ & $1 / 10$ \\
Age $(\mathrm{yr})$ & $53.3 \pm 6.5$ & $53.0 \pm 7.8$ & $55.2 \pm 8.2$ \\
Weight $(\mathrm{kg})$ & $76.6 \pm 7.6$ & $81.6 \pm 7.1$ & $82.6 \pm 9.9$ \\
BSA (m $\left.{ }^{2}\right)$ & $1.85 \pm 0.1$ & $1.95 \pm 0.1$ & $1.97 \pm 0.1$ \\
Previous myocardial infarction & 9 & 7 & 5 \\
$\beta$-adrenergic blocking dnig & 9 & 10 & 11 \\
Calcium-entry blocker & 4 & 7 & 6 \\
Digoxin & 1 & 2 & 2 \\
Ejection fraction & $0.59 \pm 0.11$ & $0.57 \pm 0.97$ & $0.60 \pm 0.08$ \\
Dyssynergy & 5 & 3 & 2 \\
\hline
\end{tabular}

Number of patients or mean values $\pm \mathrm{SD}$.

rate (HR), systolic, diastolic and mean arterial pressure (SAP, DAP, MAP), mean pulmonary arterial pressure (MPAP), mean pulmonary capillary wedge pressure (PCWP), mean central venous pressure (CVP) and cardiac output (CO). All pressures were measured with appropriate transducers zeroed to the midthoracic line and recorded with an ink-jet recorder. Mean pressures were transduced electronically and all pressures read at end-expiration. Cardiac output was measured with thermodilution using 0.9 per cent saline at room temperature and expressed as the mean of the values calculated from three well-forned curves. The following haemodynamic parameters were calculated using standard formulae: cardiac index $(\mathrm{CI})$, stroke index (SI), systemic and pulmonary vascular resistances (SVR, PVR), rate-pressure product (RPP) and coronary perfusion pressure (CPP = DAP-PCWP).

Before opening the code of treatment, three investigators evaluated separately the ECG recordings for evidence of myocardial ischaemia. This was diagnosed when a new ST-segment depression $\geqslant 1 \mathrm{~mm}$ was observed at a calibration of $10 \mathrm{~mm} / \mathrm{mV}$ in lead $V_{5}$. The ST-segment was evaluated with respect to the $P Q$ junction at a point $80 \mathrm{~ms}$ following the $\mathrm{S}$-wave nadir.

TABLE Il Arterial $\mathrm{PCO}_{2}(\mathrm{mmHg})$

\begin{tabular}{llll}
\hline & Pancuronium & Atracurium & Vecuronium \\
\hline Control & $40 \pm 3$ & $39 \pm 3$ & $39 \pm 5$ \\
Preintubation & $45 \pm 6$ & $44 \pm 5$ & $40 \pm 5$ \\
Presurgery & $38 \pm 4$ & $37 \pm 3$ & $37 \pm 3$ \\
\hline
\end{tabular}

Mean values $\pm \mathrm{SD}$.

\section{Statistical methods}

Repeated measurements analysis of variance (BMDP program 8v) ${ }^{15}$ was used to assess the significance of the changes over time and of the differences between the three groups. To supplement the analysis of variance, the $t$-test for paired data was applied to assess the significance of the changes from the control values within the groups and the t-test for unpaired data was used to compare changes between the groups. The Bonferroni allowance was used to correct for multiple pairwise testing. Fisher's exact test was applied to the frequency data to compute the exact two-tailed probabilities of observing the results due to chance, given the marginal totals.

\section{Results}

The three groups of patients were comparable with respect to preoperative characteristics (Tables I and III). Table II presents the arterial $\mathrm{PCO}_{2}$ values; the groups did not differ significantly with respect to this variable. Additional doses of the relaxants were given as follows: one dose of pancuronium, six patients; one-two doses of vecuronium, six patients; two-five doses of atracurium, 11 patients.

Table IIl and the Figure summarize the haemodynamic data. When the changes from the awake control values observed at various study periods were compared between the groups, the only significant difference between the pancuronium and atracurium groups was the greater PVR in the latter group after stemal spread. By contrast, comparison between the pancuronium and vecuronium groups revealed significant differences in HR, CI, MAP, RPP and CPP, the patients given vecuronium showing lower values in these variables than those 
TABLE III Haemodynamic variables

\begin{tabular}{|c|c|c|c|c|c|c|}
\hline & Awake & $\begin{array}{l}\text { During } \\
\text { induction }\end{array}$ & $\begin{array}{l}\text { Before } \\
\text { intubation }\end{array}$ & $\begin{array}{l}\text { After } \\
\text { intubation }\end{array}$ & $\begin{array}{l}\text { Before } \\
\text { incision }\end{array}$ & $\begin{array}{l}\text { Sternal } \\
\text { spread }\end{array}$ \\
\hline \multicolumn{7}{|l|}{ HR (beats $\mathrm{min}^{-1}$ ) } \\
\hline Pancuronium & $62.4 \pm 11.9$ & $62.4 \pm 7.0$ & $65.9 \pm 6.9$ & $65.3 \pm 6.7$ & $55.5 \pm 6.8$ & $60.4 \pm 12.6$ \\
\hline Atracurium & $62.1 \pm 6.6$ & $60.1 \pm 6.2$ & $59.5 \pm 6.8$ & $57.6 \pm 7.5$ & $49.6 \pm 5.2 \ddagger$ & $55.6 \pm 14.6$ \\
\hline Vecuronium & $61.1 \pm 7.5$ & $56.0 \pm 7.5$ & $\begin{array}{l}55.5 \pm 6.2^{*} \\
\text { PY* }\end{array}$ & $\begin{array}{l}53.5 \pm 6.3^{\dagger} \\
P P^{*}\end{array}$ & $47.3 \pm 5.0 \div$ & $49.2 \pm 4.9 \ddagger$ \\
\hline \multicolumn{7}{|l|}{$\mathrm{CI}\left(\mathrm{L} \cdot \mathrm{min}^{-1} \cdot \mathrm{m}^{-2}\right)$} \\
\hline Pancuronium & $3.35 \pm 0.72$ & $3.21 \pm 0.73$ & $3.53 \pm 0.56$ & $3.54 \pm 0.62$ & $2.61 \pm 0.57 \dagger$ & $2.94 \pm 0.78$ \\
\hline Atracurium & $2.99 \pm 0.56$ & $2.77 \pm 0.42$ & $3.00 \pm 0.64$ & $2.75 \pm 0.54$ & $2.01 \pm 0.20 \ddagger$ & $2.39 \pm 0.82$ \\
\hline Vecuronium & $3.07 \pm 0.58$ & $2.77 \pm 0.61$ & $2.81 \pm 0.70$ & $\begin{array}{l}2.54 \pm 0.55 \ddagger \\
\text { PV* }^{*}\end{array}$ & $2.07 \pm 0.54 \ddagger$ & $2.27 \pm 0.62 \ddagger$ \\
\hline \multicolumn{7}{|l|}{$\mathrm{SI}\left(\mathrm{ml} \cdot \mathrm{m}^{-2}\right)$} \\
\hline Pancuronium & $54 \pm 10$ & $51 \pm 8$ & $55 \pm 7$ & $54 \pm 8$ & $47 \pm 9$ & $49 \pm 11$ \\
\hline Atracurium & $48 \pm 9$ & $46 \pm 9$ & $50 \pm 9$ & $48 \pm 9$ & $41 \pm 7$ & $43 \pm 8$ \\
\hline Vecuronium & $50 \pm 7$ & $50 \pm 13$ & $51 \pm 12$ & $48 \pm 10$ & $44 \pm 12^{*}$ & $46 \pm 9$ \\
\hline \multicolumn{7}{|l|}{ MAP (mmHg) } \\
\hline Pancuronium & $87 \pm 13$ & $77 \pm 24$ & $83 \pm 20$ & $86 \pm 16$ & $89 \pm 13$ & $113 \pm 14 \dagger$ \\
\hline Atracurium & $91 \pm 10$ & $78 \pm 18$ & $83 \pm 19$ & $87 \pm 17$ & $81 \pm 15$ & $116 \pm 23 \dagger$ \\
\hline Vecuronium & $95 \pm 11$ & $70 \pm 9 \neq$ & $73 \pm 117$ & $79 \pm 11 \dagger$ & $71 \pm 12 \dagger$ & $97 \pm 16$ \\
\hline & & PV* & & & PVt & $\mathrm{PV}^{*} \mathrm{AV} *$ \\
\hline \multicolumn{7}{|l|}{ MPAP (mmHg) } \\
\hline Pancuronium & $17.5 \pm 4.3$ & $16.8 \pm 3.8$ & $16.5 \pm 3.2$ & $17.0 \pm 3.4$ & $15.0=2.6$ & $17.4 \pm 3.9$ \\
\hline Atracurium & $19.7 \pm 3.6$ & $17.9 \pm 3.8$ & $18.2 \pm 4.8$ & $18.8 \pm 4.3$ & $15.3 \pm 3.0$ & $20.5 \pm 4.3$ \\
\hline Vecuronium & $17.6 \pm 4.0$ & $15.5 \pm 3.8$ & $14.7 \pm 4.5$ & $15.0 \pm 3.8$ & $13.6=3.9$ & $16.6 \pm 5.2$ \\
\hline \multicolumn{7}{|l|}{ PCWP (mmHg) } \\
\hline Pancuronium & $11.4 \pm 3.7$ & $11.5 \pm 3.6$ & $11.5 \pm 2.9$ & $10.5 \pm 2.3$ & $9.8 \pm 2.4$ & $11.7 \pm 2.8$ \\
\hline Atracurium & $14.2 \pm 3.5$ & $13.4 \pm 3.5$ & $13.3 \pm 4.2$ & $13.6 \pm 3.5$ & $10.7 \pm 2.3 \dagger$ & $13.6 \pm 3.4$ \\
\hline Vecuronium & $11.2 \pm 3.5$ & $10.3 \pm 3.1$ & $10.2 \pm 3.3$ & $9.8 \pm 2.9$ & $9.1 \pm 2.0$ & $12.1 \pm 5.2$ \\
\hline \multicolumn{7}{|l|}{ CVP (mmHg) } \\
\hline Pancuronium & $6.0 \pm 2.5$ & $6.5 \pm 2.0$ & $5.8 \pm 1.9$ & $5.9 \pm 1.6$ & $5.6 \pm 1.2$ & $6.6 \pm 1.9$ \\
\hline Atracurium & $8.2 \pm 2.7$ & $8.3 \pm 2.7$ & $7.6 \pm 2.7$ & $8.8 \pm 1.9$ & $6.9 \pm 2.2$ & $7.8 \pm 2.0$ \\
\hline Vecuronium & $6.0 \pm 3.2$ & $6.1 \pm 2.8$ & $5.8 \pm 2.7$ & $6.3 \pm 2.2$ & $6.1 \pm 2.5$ & $6.1 \pm 2.7$ \\
\hline \multicolumn{7}{|c|}{ RPP (mmHg beats $\min ^{-1} \cdot 10^{-3}$ ) } \\
\hline Pancuronium & $7.98 \pm 2.41$ & $6.90 \pm 2.23$ & $7.86 \pm 1.99$ & $8.08 \pm 2.11$ & $6.90 \pm 1.18$ & $9.34 \pm 2.40$ \\
\hline Atracurium & $8.41 \pm 1.50$ & $6.97 \pm 1.61$ & $7.16 \pm 1.38$ & $7.33 \pm 1.32$ & $5.70 \pm 1.10^{\dagger}$ & $9.29 \pm 4.76$ \\
\hline Vecuronium & $8.18 \pm 1.30$ & $5.72 \pm 1.00 \ddagger$ & $5.91 \pm 0.91 \ddagger$ & $6.15 \pm 1.34 \div$ & $4.86 \pm 1.02 \ddagger$ & $6.57 \pm 1.35 \dagger$ \\
\hline \multirow{2}{*}{\multicolumn{7}{|c|}{$\mathrm{CPP}(\mathrm{mmHg})$}} \\
\hline & & & & & & \\
\hline Pancuronium & $51 \pm 9$ & $43 \pm 16$ & $49 \pm 13$ & $53 \pm 11$ & $56 \pm 10$ & $72 \pm 12 \ddagger$ \\
\hline Atracurium & $52 \pm 7$ & $43 \pm 15$ & $47 \pm 13$ & $46 \pm 14$ & $49 \pm 11$ & $71 \pm 18 \dagger$ \\
\hline Vecuronium & $54 \pm 7$ & $38 \pm 8 \dagger$ & $42 \pm 7 \dagger$ & $46 \pm 9$ & $43 \pm 10$ & $59 \pm 7$ \\
\hline & & & & & PV† & $\mathrm{PV}^{*} \mathrm{AV}^{*}$ \\
\hline \multicolumn{7}{|c|}{ SVR $\left(\right.$ dyn $\left.\cdot s \cdot \mathrm{cm}^{-3}\right)$} \\
\hline Pancuronium & $1093 \pm 263$ & $976 \pm 380$ & $962 \pm 250$ & $999 \pm 218$ & $1462 \pm 481$ & $1653 \pm 393 t$ \\
\hline Atracurium & $1176 \pm 276$ & $1071 \pm 373$ & $1086 \pm 374$ & $1208 \pm 360$ & $1518 \pm 274^{*}$ & $2000 \pm 685 \dagger$ \\
\hline Vecuronium & $1216 \pm 266$ & $999 \pm 312$ & $1015 \pm 258$ & $1191 \pm 225$ & $1342 \pm 379$ & $1713 \pm 426 \dagger$ \\
\hline \multicolumn{7}{|c|}{ PVR (dyn $\left.\cdot \mathrm{s} \cdot \mathrm{cm}^{-5}\right)$} \\
\hline Pancuronium & $80 \pm 22$ & $71 \pm 17$ & $62 \pm 17$ & $81 \pm 27$ & $88 \pm 28$ & $84 \pm 35$ \\
\hline Atracurium & $79 \pm 36$ & $69 \pm 35$ & $71 \pm 38$ & $80 \pm 34$ & $94 \pm 36^{*}$ & $126 \pm 45 t$ \\
\hline \multirow[t]{2}{*}{ Vecuronium } & $85 \pm 33$ & $79 \pm 25$ & $67 \pm 27$ & $84 \pm 23$ & $90 \pm 37$ & $87 \pm 41$ \\
\hline & & & & & & $\mathrm{PA}^{*} \mathrm{AV}^{*}$ \\
\hline
\end{tabular}

${ }^{*} p<0.05, \dagger_{p}<0.01, \ddagger p<0.001$. Significant changes within the groups and significant differences between the groups are shown. $\mathbf{P V}=$ pancuronium vs vecuronium. $\mathrm{PA}=$ pancuronium vs atracurium. $\mathrm{AV}=$ atracurium vs vecuronium.

Mean values $\pm \mathrm{SD}$ 
receiving pancuronium. The significant differences in $\mathrm{HR}$ and $\mathrm{CI}$ were observed at the time of intubation, whereas those in MAP, RPP and CPP occurred mainly in the pre- and poststernotomy periods. After sternal spread, the atracurium group had higher MAP, PVR and CPP than the vecuronium group.

Even the pancuronium group showed no obvious haemodynamic response to endotracheal intubation, the intergroup difference in $\mathrm{HR}$ and $\mathrm{CI}$ resulting mainly from the decreased values in the vecuronium group. After sternal spread, the average MAP was significantly increased in the pancuronium and atracurium groups but reached only the control level in the vecuronium group. This increase in MAP was due to an elevation of SVR.

The incidences of notable haemodynamic changes are presented in Table IV. There were significant differences between the pancuronium and vecuronium groups in the incidence of marked bradycardia ( $\mathrm{HR}<45$ beats $\mathrm{min}^{-1}$ ) and in the incidence of $H R$ exceeding the control value by 10 beats $\mathrm{min}^{-1}$. A decrease in systolic arterial pressure necessitating treatment with ephendrine $(<80$ $\mathrm{mmHg}$ ) was observed in one patient and he had received pancuronium. Flushing was not seen in any of the patients.

Five patients showed significant $(0.1-0.15 \mathrm{mV})$ ST-segment depression during the awake control stage, but these ECG findings remained unchanged during the later study periods. New electrocardiographic changes of myocardial ischaemia were noted in two patients receiving pancuronium and in two given atracurium. One patient of the pancuronium group and another of the atracurium group showed ST-segment depression after sternotomy. The former patient had an increase in HR from the control value of 78 to 96 beats $\mathrm{min}^{-1}$ and the latter from 62 to 100 beats $\cdot \mathrm{min}^{-1}$. In the other two patients, ST-segment depression occurred after the administration of the muscle relaxant. In the patient receiving pancuronium, HR was decreased and in the patient receiving atracurium, HR increased only slightly. However, both these patients experienced a decrease in CPP (P: from 55 to $40 \mathrm{mmHg}$; A: from 51 to $38 \mathrm{mmHg}$ ).

\section{Discussion}

In our pancuronium group, no changes were observed in the mean values of HR, MAP or any other

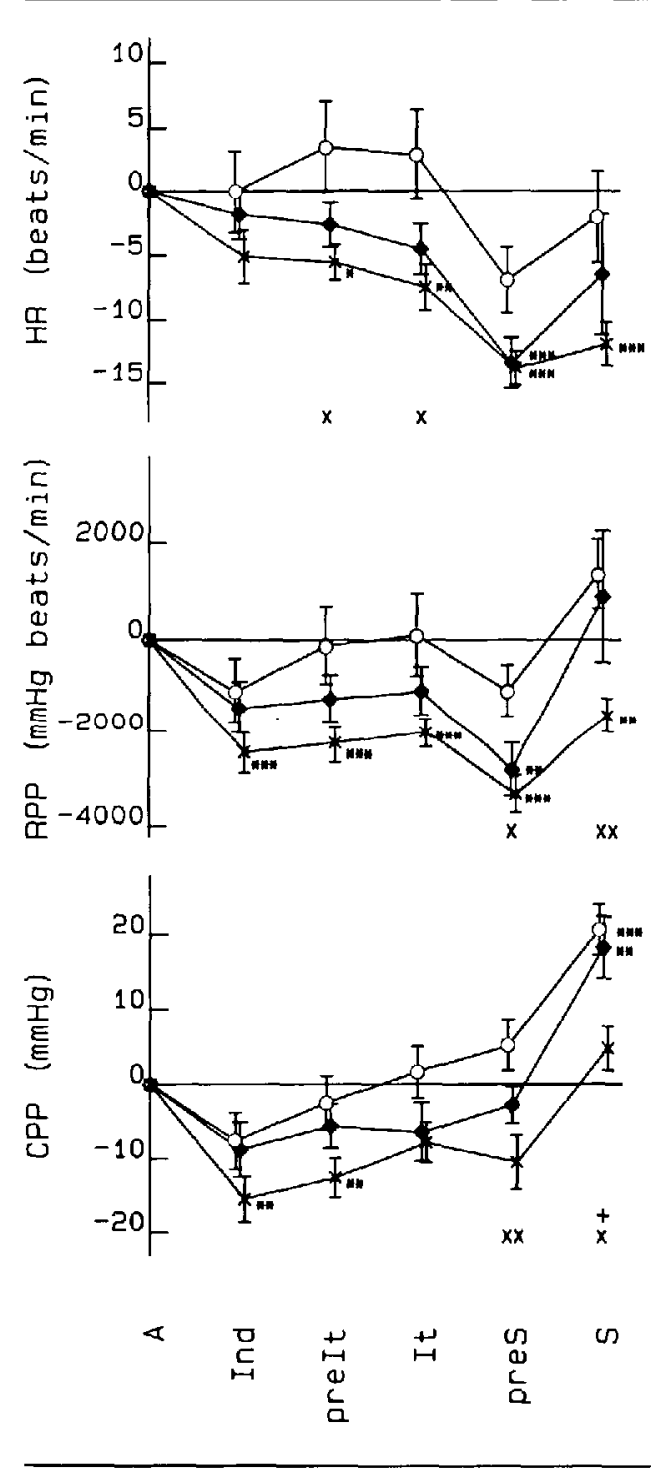

FIGURE Changes from the awake control values of heart rate, rate-pressure product and coronary perfusion pressure induced by pancuronium $(O)$, atracurium $(\bullet)$ and vecuronium $(X)$ during high-dose fentanyl anaesthesia. $A=$ awake control, Ind = during induction of anaesthesia, prelt = before intubation, It $=$ after intubation, pre $S=$ before the start of surgery, $S=$ after stemal spread. ${ }^{*} p<0.05 ;{ }^{* *} p<0.01 ;{ }^{* * *} p<$ 0.001 ; significant change within the group. $x, p<0.05$; $x \times, p<0.01$; significant difference between pancuronium and vecuronium groups.,$+ p<0.05$; significant difference between atracurium and vecuronium groups. 
TABLE IV Incidence of ST-segment depression and important haemodynamic changes

\begin{tabular}{llll}
\hline & $\begin{array}{l}\text { Pancuronium } \\
n=11\end{array}$ & $\begin{array}{l}\text { Atracurium } \\
n=12\end{array}$ & $\begin{array}{l}\text { Vecuronium } \\
n=1 I\end{array}$ \\
\hline ST-segment depression $\geq 0.1 \mathrm{mV}$ & 2 & 2 & 0 \\
HR $<45$ beats $\cdot \mathrm{min}^{-1}$ & 0 & 2 & $5^{*}$ \\
$\mathrm{HR}>$ control +10 beats $\cdot \mathrm{min}^{-1}$ & 5 & 1 & $0^{*}$ \\
$\mathrm{HR}>$ control +20 beats $\cdot \mathrm{min}^{-1}$ & 1 & 1 & 0 \\
$\mathrm{SAP}<90 \mathrm{mmHg}$ & 4 & 2 & 3 \\
SAP $>160 \mathrm{mmHg}$ & 3 & 5 & 2 \\
RPP $>10000 \mathrm{mmHg} \cdot$ beats $\cdot \mathrm{min}^{-1}$ & 4 & 3 & 0 \\
\hline
\end{tabular}

${ }^{*} \mathrm{p}=0.035$; pancuronium vs vecuronium.

haemodynamic variable after the administration of the relaxant or after intubation. These findings are in agreement with those of others who have studied similar patients during high-dose fentanyl anaesthesia. ${ }^{16-18}$ However, others have reported an increase in HR after the administration of pancuronium $^{2,19,20}$ or significant haemodynamic responses to intubation. ${ }^{19}$ In all these studies the dose of fentanyl was about the same and there were no great differences between the patient populations studied. However, in the studies in which an increase in $\mathrm{HR}$ was observed, either the beta-blockers were withheld from the night prior to surgery ${ }^{19,20}$ or diazepam was not given before fentanyl. ${ }^{2}$ Diazepam in doses as small as used in the present study has been shown to convert the small increase in plasma catecholamines seen during induction of fentanyl-metocurine anaesthesia into a decrease and to significantly affect the haemodynamic course of the anaesthetic induction. ${ }^{21}$

The post-relaxant haemodynamics of the present study are broadly comparable to those of our previous study in which pancuronium or vecuronium was administered after the patients had recovered from succinylcholine-induced neuromuscular block. ${ }^{6}$ It is therefore probable that succinylcholine does not significantly modify haemodynamic responses to pancuronium or vecuronium during high-dose fentanyl anaesthesia preceded by intravenous diazepam.

As in our pancuronium group, we found no significant changes in the mean haemodynamic values of our atracurium group after the administration of the relaxant and after intubation. Furthermore, the incidences of hypotension and tachycardia were not greater in the atracurium group than in the other study groups and flushing was not ob- served in any of the patients receiving atracurium. These haemodynamic findings are in agreement with those of Starr et al. ${ }^{22}$ who gave a similar dose of atracurium during high-dose fentanyl anaesthesia. However, Skourtis et al. ${ }^{23}$ reported a significant decrease in MAP and SVR after a bolus dose of $0.35 \mathrm{mg} \cdot \mathrm{kg}^{-1}$ of atracurium during high-dose fentanyl anaesthesia although a dose of $0.3 \mathrm{mg} \cdot \mathrm{kg}^{-1}$ did not produce any haemodynamic changes. In addition, in another study, one of the 16 patients with coronary artery disease exhibited a typical circulatory histamine response after a bolus dose of $0.3 \mathrm{mg} \cdot \mathrm{kg}^{-1}$ of atracurium during lorazepam- $\mathrm{N}_{2} \mathrm{O}$ fentanyl anaesthesia. ${ }^{24}$ Almost all patients of our atracurium group required an additional dose of the relaxant before stemotomy. It is, however, uncertain whether the small increase in PVR observed in our patients at the time of sternotomy is due to histamine release. There is some evidence that it is the size of the bolus dose of atracurium and not the total dose that will determine the occurrence of haemodynamic changes. ${ }^{23}$ Although we found no clinical signs of histamine release after a rapid injection of a dose of atracurium permitting intubation, it is probably wise to inject such doses slowly in order to avoid histamine-induced circulatory changes in occasional patients. ${ }^{25}$ Perhaps the administration of the $\mathrm{H}_{1}$ antagonist promethazine on the evening before surgery may have influenced the haemodynamic response to atracurium in this study.

The differences in HR, CI and MAP between our vecuronium and pancuronium groups may be explained by the vagolytic and sympathomimetic effects of pancuronium which tended to counteract the depressing effect of fentanyl on these variables. ${ }^{6}$ In addition, our previous results suggest that vecuronium might have a moderate negative chrono- 
tropic effect. ${ }^{6}$ However, no change in HR after vecuronium was observed in some other studies made in patients undergoing CABG under highdose fentanyl ${ }^{22,26}$ or halothane anaesthesia. ${ }^{5}$ In the present study, the incidence of marked bradycardia ( $\mathrm{HR}<45$ beats $\cdot \mathrm{min}^{-1}$ ) was about the same as in our previous study; ${ }^{6}$ however, sinus rhythm was maintained in all patients in these studies after vecuronium. An advantage of vecuronium over pancuronium and atracurium was the attenuation of blood pressure response to sternotomy.

The incidence of myocardial ischaemia before surgery was somewhat smaller in our patient groups (P 1/11; A 1/12; V 0/11) than that recently reported by Thomson and Putnins ${ }^{2}$ in a patient group given pancuronium during the induction of high-dose fentanyl anaesthesia (3/12). Furthermore, in our patients ischaemia before surgery was not associated with an increase in HR and RPP, as was the case in Thomson's patients, but might rather be due to a decrease in CPP. However, no patient given vecuronium developed myocardial ischaemia despite a decrease in CPP during the induction of anaesthesia. In addition, no patient of the vecuronium group showed tachycardia or ST-segment depression during sternotomy. Larger patient groups are obviously needed to find out whether there is a real difference in the incidence of myocardial ischaemia between patients receiving various muscle relaxants.

The doses of the muscle relaxants used in the present study were calculated from the dose response curves obtained by Gramstad and Lilleaasen ${ }^{27}$ who used a cumulative dose regimen. Although a single bolus dose technique is obviously preferable for determining potency for relatively short-acting drugs like vecuronium and atracurium, ${ }^{28}$ the potency ratios obtained with these two methods do not seem to differ significantly. ${ }^{29}$

In summary, when administered during highdose fentanyl anaesthesia in patients under betaadrenergic blockade and pretreated with iv diazepam, pancuronium did not produce increases in heart rate, arterial pressure or cardiac output, whereas patients given vecuronium showed a decrease in these variables. The haemodynamic effects of atracurium were intermediate compared with the other two relaxants. In spite of a decrease in coronary perfusion pressure no patient given vecuronium developed myocardial ischaemia. An advantage of vecuronium over pancuronium and atracurium was an attenuation of the haemodynamic response to sternotomy.

\section{Acknowledgements}

This study was supported by the Paulo Foundation, Finland.

\section{References}

1 Savarese $J J$, Lowenstein E. The name of the game: no anesthesia by cookbook. Anesthesiology 1985; 62: 703-5.

2 Thomson IR, Putnins $C L$. Adverse effects of pancuronium during high-dose fentanyl anesthesia for coronary artery bypass grafting. Anesthesiology 1985; 62: 708-13.

3 Basta JW, Lichtiger $M$. Comparison of metocurine and pancuronium-Myocardial tension-time index during endotracheal intubation. Anesthesiology 1977; 46: 366-8.

4 Heinonen J, Yrjölä $H$. Comparison of haemodynamic effects of metocurine and pancuronium in patients with coronary artery disease. $\mathrm{Br} \mathrm{J}$ Anaesth 1980; 52: 931-7.

5 Morris RB, Cahalan MK, Miller RD, Wilkinson PL, Quasha $A L$, Robinson $S L$. The cardiovascular effects of vecuronium (ORG NC45) and pancuronium in patients undergoing coronary artery bypass grafting. Anesthesiology 1983; 58: 438-40.

6 Salmenperä M, Peltola K, Takkunen O, Heinonen $J$. Cardiovascular effects of pancuronium and vecuronium during high-dose fentanyl anesthesia. Anesth Analg 1983; 62: 1059-64.

7 Durant NN, Marshall IG, Savage DS, Nelsan DJ, Sleigh T, Carlyle IC. The neuromuscular and autonomic blocking activities of pancuronium, ORG $\mathrm{NC45}$, and other pancuronium analogues in the cat. $\mathrm{J}$ Pharm Pharmacol 1979; 31: 831-6.

8 Bowman WC, ed.. The pharmacology of neuromuscular function. Bristol: John Wright and Sons Ltd, 1980: 105.

9 Docherty JR, McGrath JC. A comparison of the relaxant and autonomic effects of pancuronium and its monoquaternary derivative Organon NC45 in the pithed rat. Br J Pharmacol 1980; 68: 140-1P.

10 Hughes $R$, Chapple DJ. The pharmacology of atracurium: a new competitive neuromuscular blocking agent. Br J Anaesth 1981; 53: 31-44. 
11 Sutherland GA, Squire IB, Gibb AJ, Marshall IG. Neuromuscular blocking and autonomic effects of vecuronium and atracurium in the anaesthetized cat Br J Anaesth 1983; 55: 1119-26.

12 Basta SJ, Savarese JJ, Ali HH et al. Vecuronium does not alter serum histamine within the clinical dose range. Anesthesiology 1983; 59: A273.

13 Basta SJ, Savarese JJ, Ali HH, Moss J, Gionfriddo $M$. Histamine-releasing potencies of atracurium besylate (BW 33A), metocurine, and D-tubocurarine. Anesthesiology 1982; 57: A261.

14 Nigrovic $V$. Succinylcholine, cholinoceptors and catecholamines: proposed mechanism of early adverse haemodynamic reactions. Can Anaesth Soc J 1984; 31: 382-94.

15 Dixon WJ. BMDP Statistical Software 1981, Department of Biomathematics. Berkeley; University of California Press, 1981.

16 Edde $R R$. Hemodynamic changes prior to and after sternotomy in patients anesthetized with high-dose fentanyl. Anesthesiology 1981; 55: 444-6.

17 Quintin L, Whalley DG, Wynands JE, Morin JE, Burke $J$. High dose fentanyl anaesthesia with oxygen for aorto-coronary bypass surgery. Can Anaesth Soc J 1981; 28: 314-20.

18 Howie MB, MCSweeney TD, Lingam RP, Maschke $S P$. A comparison of fentanyl- $\mathrm{O}_{2}$ and sufentanil- $\mathrm{O}_{2}$ for cardiac anesthesia. Anesth Analg 1985; 64: 87787.

19 Waller JL, Hug CC, Nagle DM, Craver JM. Hemodynamic changes during fentanyl-oxygen anesthesia for aorto-coronary bypass operation. Anesthesiology 1981; 55: 212-7.

20 Thomson IR, Mutch WAC, Culligan JD. Failure of intravenous nitroglycerin to prevent intraoperative myocardial ischemia during fentanyl-pancuronium anesthesia. Anesthesiology 1984; 61: 385-93.

21 Tomicheck RC, Rosow CE, Philbin DM, Moss J, Teplick RS, Schneider RC. Diazepam-fentanyl interaction - hemodynamic and hormonal effects in coronary artery surgery. Anesth Analg 1983; 62: 881-4.

22 Starr NJ, Sethna DH, Samonte AF, Estafanous FG. Hemodynamic comparison of non-depolarizing muscle relaxants: a randomized prospective study. Anesth Analg 1985; 64: 287.

23 Skourtis CT, Athanasiadis C, Ali HH, Lappas DG, Mikelakos $\boldsymbol{P}$. Neuromuscular and circulatory responses to atracurium during administration of highdose of fentanyl. Anesth Analg 1985; 64: 282.
24 Philbin DM, Machaj VR, Tomicheck RC et al. Haemodynamic effects of bolus injection of atracurium in patients with coronary artery disease. $\mathrm{Br} \mathrm{J}$ Anaesth 1983; 55: 131-4S

25 Scott RPF, Savarese JJ, Ali HH et al. Atracurium: clinical strategies for preventing histamine release and attenuating the hemodynamic response. Anesthesiology 1984; 61: A287.

26 Gallo JA, Freis E, Schneider RC, Basta SJ, Philbin $D M$. Hemodynamic effects of bolus injection of vecuronium in cardiac surgical patients. Anesthesiology 1984; 61: A63.

27 Gramstad L, Lilleaasen P. Dose-response relation for atracurium, ORG NC45 and pancuronium. Br J Anaesth 1982; 54: 647-51.

28 Gibson FM, Mirakhur RK, Clarke RSJ, Lavery GG Comparison of cumulative and single bolus dose techniques for determining the potency of vecuronium. Br J Anaesth 1985; 57: 1060-2.

29 Gramstad L, Lilleaasen $P$. Neuromuscular blocking effects of atracurium, vecuronium and pancuronium during bolus and infusion administration. Br J Anaesth $1985 ; 57$ : 1052-9. 


\section{Résumé}

Afin de définir le rôle des relaxants musculaires dans les réponses hémodynamiques aux hautes doses $\left(75 \mu \mathrm{g} \cdot \mathrm{kg}^{-1}\right)$ de fentanyl et à la stimulation associée d l'intubation et l'écartement sternal durant la chirurgie pour pontage aortocoronarien, on a comparé l'hémodynamie entre trois groupes de patients ayant reçu soit du pancuronium 10.1 $\left.\mathrm{mg} \cdot \mathrm{kg}^{-1}, n=11\right)$, soit du vecuronium $\left(0.086 \mathrm{mg} \cdot \mathrm{kg}^{-1}\right.$, $n=11$ ), soit l'atracurium $\left(0.43 \mathrm{mg} \cdot \mathrm{kg}^{-1}\right), n=12$ ). Des doses additionnelles de relaxants musculaires ont été données afin de maintenir le bloc neuromusculaire à 90 pour cent. Les patients ayant reçu du pancuronium n'ont pas démontré une augmentation dans les valeurs moyennes de la fréquence cardiaque, la pression artérielle ou le débit cardiaque lors de l'induction de l'anesthésie et après intubation. Ces variables cependant ont diminué chez le groupe ayant reçu du vecuronium. Pour le groupe atracurium, les valeurs hémodynamiques ont êté intermédiaires comparativement aux deux autres groupes étudiés. Malgré une diminution de la pression de perfusion coronarienne, aucun patient ayant reçu du vecuronium n'a développé de l'ischémie myocardique. Com. parativement au pancuronium et l'atracurium, l'avantage du vecuronium était représenté par une atténuation de la tension artérielle en réponse à la sternotomie. Les patients ayant reçu de l'atracurium ont présenté une augmentation minime de la résistance vasculaire pulmonaire lors de la sternotomie. Nos patients ont continué leur médication habituelle aux antagonistes bêta-adrénergiques jusqu' au matin de l'opération et ont reçu une perite dose intraveineuse de diazepam $\left(0.1 \mathrm{mg} \cdot \mathrm{kg}^{-1}\right)$ avant l'induction de l'anesthésie. Ces médicaments peuvent avoir prévenu les effets hémodynamiques néfastes observés par d'autres investigateurs après l'administration du pancuronium lors de l'anesthésie au fentanyl à haute dose. 